morphology, the altered signalling of common diseases, the need to recognise as normal things that were once always abnormal, such as loss of lower limb reflexes and vibration sense. My only comfort has been to see others, consultants in general medicine, flounder at the bedside like myself and conclude the consultation with the words, "I'll have to take him in"-but to a ward where no one had studied the height of beds and chairs and where the more abundant nursing staff got by with charm and kindness but could be seen dragging the stroke patient up the bed by the fulcrum of the axilla, watched by the ward sister.

I don't mind whether one specialty swallows another. I do not like to envisage a situation where dog eats dog. I would like to see everyone taught the principles now known about the management of elderly patients from the beginning of his career. General medicine has become rather old hat, and not to be trusted when $40^{\circ}{ }^{\circ}$ of surgery and home consultations are concerned with pensioners I am more afraid of making mistakes in patient management than of words to describe the specialty into which it might best be fitted.

M KeIth Thompson

Croydon, Surrey

Echocardiography in mitral valve prolapse

SIR,-The echocardiogram published as part of the short report by Dr D Krikler and others (22 May, p 1257) is not diagnostic of mitral valve prolapse. In order to make a confident diagnosis of this condition from the echogram it is necessary that the anterior and posterior leaflets be displayed throughout the whole of the cardiac cycle and that the two leaflets shall be seen to come together at the beginning and the end of systole.

In the normal subject echoes from the two cusps can be separated in systole if the echoing point is not at the free margin of the two cusps which come into apposition (point A in the figure). If the echoes are derived from a position nearer the valve ring, such as point $B$, they will be separated in systole. During the course of echography it is possible,

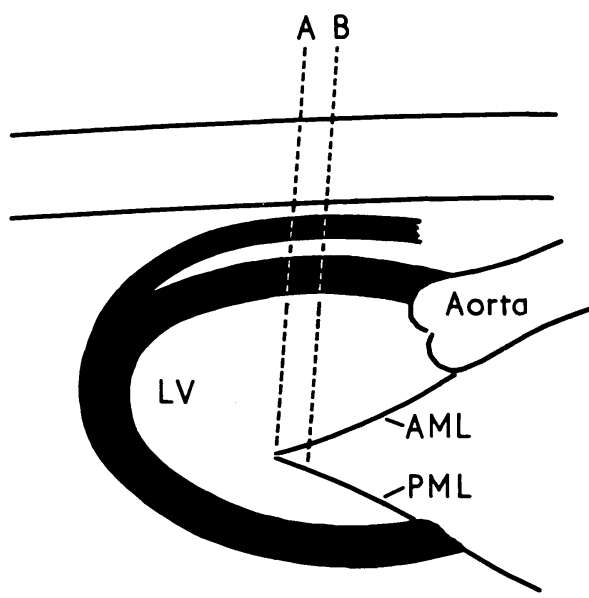

Diagram of cross-section of left ventricle (LV). $\mathbf{A}=$ Direction of an ultrasound beam in which anterior and posterior mitral cusps come into apposition at the beginning and end of systole. $\mathrm{B}=$ Beam position with separation of cusps. $\mathrm{AML}=$ Anterior mitral leaflets. PML $=$ Posterior mitral leaflets. owing to the rotation of the heart about a horizontal as well as a vertical axis, for the transducer beam to move from point $A$ to point $B$ and back again. In order to be sure that all the echoes come from the free margin it is therefore imperative that apposition shall be demonstrated both at the beginning and the end of systole; unless these strict criteria are used over-diagnosis of mitra valve prolapse will occur.

Department of Radiology,

Ronald B PRIDIE Harefield Hospital

\section{Bites from black snakes}

SIR,-Encounters between people and snakes, either accidental or provoked, become more frequent as the summer holidays bring people into the countryside. In the management of snake bite it is important to ascertain whether or not the snake was an adder, and it is said that adders can be identified by the bold V-shaped marks on their backs. The following case history may be of interest.

In May last year a 23-year-old man saw a snake in the New Forest and tried to pick it up. He wa bitten on the left index finger. The snake was about one foot $(30 \mathrm{~cm})$ long and black, and the man, who had a keen amateur interest in snakes, was sure that it did not have the markings of an adder. A few days previously considerable publicity had been given to the discovery of an escaped tropical snake in a Southampton garden, and it was with this in mind that in the casualty department we gave the patient intramuscular hydrocortisone. Two hours after the bite the finger became inflamed and inflammation then extended to the entire arm. The resulting painful and grossly swollen arm necessitated the patient spending four days in hospital before it resolved sufficiently to permit his discharge.

Subsequent inquiry revealed that melanistic forms of adder are known, and are said to be particularly common in the New Forest. This, together with the severity of the reaction, leads us to conclude that our patient was bitten by an adder. We intend to treat any future bites from black snakes as adder bites.

D J P BARKER

Royal South Hants Hospital, K J FOSTER Southampton

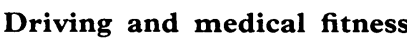

SIR,-Dr G W Roberts (15 May, p 1210) expresses concern about the medical consequences of issuing driving licences valid to the age of 70 with three-year renewals thereafter. He mentions that the law now requires drivers to inform the Licensing Centre as soon as they become aware that they are suffering from any condition which may affect their ability to drive either now or in the future. Under the new rules there is of course no statutory obligation on doctors to notify the Licensing Centre, but doctors are asked to advise their patients about their obligation in this respect.

I can happily reassure Dr Roberts that his fears that the whole procedure would not work are in practice ill founded. Already during our first six months' experience with the new arrangements we have found that they are in fact working extremely well, thanks to the interest shown by clinicians both in general and in hospital practice. I am pleased to report that doctors are raising the question of driving with patients, who are in turn notifying their complaints in accordance with the new rules. The effective procedures which worked previously are continuing to operate and in fact are operating most successfully.

Dr Roberts makes the ingenious but I fear impracticable suggestion that health declarations should be made in relation to the annual licensing of vehicles. Registered keepers of vehicles are not necessarily drivers, nor are they necessarily related to drivers of the vehicles registered. It would be quite unreasonable to impose a legal obligation on these keepers to make inquiries into the health of drivers. Finally, Dr Roberts refers to the value of "an independent driving test." One of the improvements in the new arrangements is that driving examiners are no longer asked to make recommendations beyond their competence. The 1974 Road Traffic Act placed the responsibility to make recommendations in respect of fitness to drive in progressive medical conditions on doctors and not on driving examiners. Previously the examiner had been expected to assess the effect of disabilities on fitness to drive at the time of the driving test in complaints which could change dramatically subsequently-multiple sclerosis is a good example.

The implication in Dr Roberts's letter is that the matter of checking disabilities is left entirely to the discretion of the driver. But this is certainly not the case. Licences until the age of 70 are not issued to persons who are found to have medical disabilities relevant or prospectively relevant to driving safety. These persons have licences issued with a validity of one, two, or three years.

JOHN TAYLOR

Department of the Environment, Driver and Vehicle Licensing Centre,
Swansea

\section{Fits and fitness to drive}

SIR,-Occasionally British journals would be well advised to adopt the transatlantic practice of the signed leading article so that readers can more readily gauge its gravitas. Your leading article (22 May, p 1235) on fits and fitness to drive epitomises the desirability of the signed presentation. It was clearly designed to be more authoritative than an annotation of the new edition of Medical Aspects of Fitness to Drive ${ }^{1}$ yet is uneven in the treatment of the issues involved.

The presentation leaves one wondering whether in future these regulations will be applied automatically or whether there is a continuing need for expert medical judgment and the evaluation of specialist reports in determining the reliability of the evidence or, for example, in deciding whether a person with nocturnal status epilepticus can be considered safe to drive. There is the need for a straightforward explanation of the present laws and regulations, but this will fail to satisfy those closely involved with the medical problems of fitness to drive. We await a comprehensive distillation of the case experience of the medical advisers to the Department of the Environment so that the practicality of recent rulings may be adequately assessed.

One of the weaker features of the article is the apparent support for the empirical approach to improving seizure control by a casual increase in dosage or the addition of another drug. Wherever possible, medical 
practice should include the measurement of serum levels and the avoidance of polypharmacy; and drug firms should cease the manufacture of combined tablets of phenobarbitone and of anticonvulsants whose major action is to increase the serum levels of other more active preparations.

The debate has been narrowed to epilepsy and the private motorist. Why, one may ask, is a person with a history of epilepsy, perhaps in the distant past, provided with a special licence and thus discriminated against, whereas psychiatric illness, visual defects, or cardiovascular diseases before 70 years of age do not affect a person's fitness to hold an ordinary licence? Should the same regulations govern motor boats, light aircraft, or gliders? What obligation has a doctor to give correct and early advice to a person who has had a fit after years of age before he univittingly seeks a career driving public service or heavy goods vehicles or undertakes work dependent on long hours at the wheel?

Department of Neurology,

Royal Infirmary,

Preston, Lancs

Raffle, A, ed, Medical Aspects of Fitness to Drive, 3rd edn. London, Medical Commission on Accident Prevention, 1976.

$*_{*}^{*}$ The first sentence of our article implies that doctors are expected to assess and advise patients on the effects of any disability on driving in the light of the new regulations. Like all the laws of the land, the driving licence regulations have to be applied automatically, but when assessment of individual cases is a maiter for expert medical judgment specialist advice will be obtained. In our article the current regulations were set out in detail and the interpretation and application of the regulations were outlined in a way that (it was hoped) would satisfy those closely concerned. It was not, of course, suggested that advice to alter treatment for a recurrent fit would be casual, and we agree with Dr Critchley that measurement of serum drug levels and avoidance of combined tablets and of polypharmacy are important in the modern management of epilepsy. These current views about methods of improving seizure control are well worth emphasising, though one could hardly expect to encompass all possible aspects within the constraints of a leading article focusing on fitness to drive.

Dr Critchley is not correct in saying that psychiatric illness, visual defects, or cardiovascular diseases before 70 years of age do not affect a person's fitness to hold an ordinary licence. In fact, licence holders are required by law to inform the Licensing Centre as soon as they became aware that they are suffering from any "relevant" disability (that is, one likely to cause the driving of a vehicle to be a source of danger to the public), or a "prospective" disability which, by virtue of its intermittent or progressive nature or otherwise, may in time become a relevant disability. In such cases, where appropriate, the licence is revoked or replaced by a more limited licence.-ED, $B M Y$.

\section{Meditation or methyldopa?}

SIR,-A key statement in your leading article (12 June, p 1421) on this subject requires considerable qualification if it is not to be grossly misleading.
You state that "a well-conducted and controlled clinical trial of antihypertensive treatment in the United States in men with diastolic blood pressures between 90 and $115 \mathrm{~mm} \mathrm{Hg}$ showed that the death rate from hypertension was reduced significantly and the overall incidence of complications correspondingly diminished." It is essential to note three points about the important trial ${ }^{1}$ to which you refer: (a) definite evidence of benefit was found only in those with a diastolic pressure of $105 \mathrm{~mm} \mathrm{Hg}$ or over; (b) the diastolic pressure was recorded at the fifth phase, not at the fourth phase as is customary in Britainthe fourth phase is on average at least $5 \mathrm{~mm} \mathrm{Hg}$ higher; and $(c)$ the blood pressures on which the study was based were not the patients' "casual" pressures, which would probably have been at least $5 \mathrm{~mm} \mathrm{Hg}$ higher.

Thus it is probably true to say that there is as yet no conclusive evidence of benefit from antihypertensive treatment in the case of middle-aged men with "casual" fourth-phase diastolic pressures below $115 \mathrm{~mm} \mathrm{Hg}$."

DAVID SHORT

Cardiac Department,

Aberdeen Royal Infirmary, Aberdeen

Veterans Administration Cooperative Study Group, fournal of the American Medical Association, 1970, 213, 1143 Short, D, British Heart fournal, 1975, 37, 893.

\section{Nodular vasculitis of tuberculous origin in an elderly woman}

SIR,-Classical descriptions of the Bazin form of erythema induratum emphasise its preponderance in young women. However, at least five cases of Bazin's disease have been reported in women aged $51-57 . .^{2}$

Nodular vasculitis, on the contrary, affects chiefly women aged $30-60 . .^{3}$ The syndrome is a hypersensitivity reaction to many causes, of which tuberculosis is one, and in a number of cases the exact cause of this clinical entity remains obscure. In some such cases the response to prolonged antituberculosis therapy provides the solution." Since we have diagnosed nodular vasculitis of tuberculous origin in a woman aged 84 we wish to draw attention to the fact that at any age tuberculosis has still to be considered as a cause of chronic nodular lesions of the legs.

An 84-year-old woman had been well until two months previously, when she noticed the eruption of tender nodules on both her legs. There were no other symptoms. On examination multiple tender, subcutaneous, red and purplish nodules without ulceration were present on the anterior aspects of the legs below the knees, the inner aspect of the right ankle, and the dorsa of the feet. The nodules ranged in size from 1 to $2 \mathrm{~cm}$, some of them forming plaques. No other abnormalities were found.

The urine was normal. The haematocrit value was $40^{\circ} \ldots$. The white cell count was $8.2 \times 10^{9} 1$ $\left(8200 \mathrm{~mm}^{3}\right)$ with a normal differential count and the platelet count was $143 \cdot 10^{9} / 1\left(143000 / \mathrm{mm}^{3}\right)$. The ESR was $55 \mathrm{~mm}$ in 1 hour (Westergren). C-reactive protein was present $(\ldots \ldots)$. The antistreptolysin titre was 125 Todd units. Rheumatoid factor, antinuclear antibodies, and LE cells were not found. The total plasma protein was $87 \mathrm{~g} / \mathrm{l}$ with albumin $48 \mathrm{~g} / \mathrm{l}$ and globulin $39 \mathrm{~g} / \mathrm{l}$, with and increase in the gamma component $\left(34^{\circ}{ }^{\circ}\right)$. A skin tuberculin test (OT 1:10000) was positive $(-\ldots$.$) . No mycobacteria or other pathogens were$ found in the sputum or urine. A throat culture was negative for $\{$-haemolytic streptococci. $X$-ray and tomography of the chest showed no abnormalities. Biopsy of a skin nodule revealed typical tubercle formation with caseation. Treatment with streptomycin, isoniazid, and ethambutol was initiated. During the next 20 days some of the lesions became smaller and a few healed, leaving atrophy. The patient was then discharged to continue the same treatment. Two months later no skin lesions were present and after eight months the patient was well and the plasma $\gamma$-globulin level and the ESR were normal.

Nodular vasculitis among the middle-aged or elderly is not often attributed to tuberculosis. The tuberculous origin of nodular vasculitis is too seldom considered a possibility in the differential diagnosis of leg nodules in the elderly. Personal and family history and radiological, histological, and bacteriological investigations may at times fail to disclose any evidence of tuberculosis." In unexplained cases of nodular vasculitis a strongly positive tuberculin reaction ${ }^{4}$ combined with an increase of $y_{\text {-globulin concentration }}{ }^{3}$ should suggest the possibility of tuberculosis and the response to adequate and prolonged antituberculosis therapy" : " may confirm this diagnosis."

St K BARTSOKAS

J Stratigos

A ARCHIMANDRITIS

G Rigatos

$S$ BEGIETI

Department of Pathological Physiology,

Section of Internal Medicine,

National University of Athens, Greece

Montgomery, H, O'Leary, P A, and Barker, N W, Collected Papers of the Mayo Clinic, 1944, 36, 461. Feiwel, M, and Munro, D D, British Medical fournal, 1965, 2, 1109.

Rook, A, Wilkinson, D S, and Ebling, F J G, Textbook of Dermatology. vol 1, p 675. Oxford and Edinburgh, Blackwell Scientific, 1969.

Stegmaier, O, Archives of Dermatology, 1959, 80, 350. British Mcdical Fournal, 1963, 2, $98 \mathrm{i}$

'Benians, R G, British Medical fournal, 1963, 2, 1267.

\section{Natural history of chronic bronchitis}

SIR,-In your leading article on this subject (29 May, p 1297) you start with the hypothesis that mucopurulent bronchitis is a stage on the road to obstructive bronchitis, with a reference ${ }^{1}$ in which I can find no evidence for this claim. You follow by stating that infection is one of the factors leading to the "development and progression" of bronchitis, with a reference to the late Professor J R May's book on the chemotherapy of chronic bronchitis ${ }^{2}$ in which I can find no evidence to support this statement. Indeed, the preface only claims that "it may be that long continued effective suppression of the relevant pathogenic bacteria will ultimately be shown to delay the progressive deterioration of pulmonary function to which most bronchitics are subject." Finally you state, without any references, that the bronchitic's "respiratory function invariably worsens" with mucopurulent episodes.

In a leading article in 1973:" you made the same claim about the effects of respiratory infections on lung function in bronchitis and

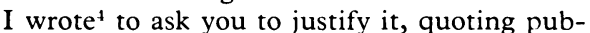
lications which showed that they very rarely have any permanent effect. A further paper confirming this evidence has recently been published." And surely the finding by Johnston and his colleagues, ${ }^{6}$ which you quote, that antibiotic treatment had no effect on the decline in forced expiratory volume makes it improbable that infection itself has much effect on it. 